\title{
Obstructive and restrictive spirometric patterns: fixed cut-offs for $\mathrm{FEV}_{1} / \mathrm{FEV} 6$
} and FEV6

\author{
J. Vandevoorde*, S. Verbanck\# , D. Schuermans ${ }^{\#}$, J. Kartounian* and W. Vincken ${ }^{\#}$
}

ABSTRACT: The purpose of this study was to determine fixed cut-off points for forced expiratory volume in one second (FEV 1 /FEV6 and FEV 6 as an alternative for FEV1/forced vital capacity (FVC) and FVC in the detection of obstructive and restrictive spirometric patterns, respectively.

For the study, a total of 11,676 spirometric examinations, which took place on Caucasian subjects aged between 20-80 yrs, were analysed. Receiver-operator characteristic curves were used to determine the $\mathrm{FEV}_{1} / \mathrm{FEV} 6$ ratio and FEV 6 value that corresponded to the optimal combination of sensitivity and specificity, compared with the commonly used fixed cut-off term for FEV1/FVC and FVC.

The data from the current study indicate that $\mathrm{FEV}_{1} / \mathrm{FEV}_{6}<\mathbf{7 3} \%$ and $\mathrm{FEV}_{6}<\mathbf{8 2} \%$ predicted can be used as a valid alternative for the $\mathrm{FEV}_{1} / \mathrm{FVC}<\mathbf{7 0} \%$ and $\mathrm{FVC}<\mathbf{8 0} \%$ pred cut-off points for the detection of obstruction and restriction, respectively. The statistical analysis demonstrated very good, overall, agreement between the two categorisation schemes. For the spirometric diagnosis of airway obstruction (prevalence of $45.9 \%$ ), FEV $1 / F_{6}$ sensitivity and specificity were 94.4 and 93.3\%, respectively; the positive and negative predictive values were 92.2 and $95.2 \%$, respectively. For the spirometric detection of a restrictive pattern (prevalence of 14.9\%), FEV6 sensitivity and specificity were 95.9 and $\mathbf{9 8 . 6 \%}$, respectively; the positive and negative predictive values were 92.2 and $99.3 \%$, respectively.

This study demonstrates that forced expiratory volume in one second/forced expiratory volume in six seconds $<73 \%$ and forced expiratory volume in six seconds $<82 \%$ predicted, can be used as valid alternatives to forced expiratory volume in one second/forced vital capacity $<70 \%$ and forced vital capacity $<\mathbf{8 0} \%$ predicted, as fixed cut-off terms for the detection of an obstructive or restrictive spirometric pattern in adults.

KEYWORDS: Chronic obstructive pulmonary disease, forced expiratory volume in six seconds, pulmonary function testing, spirometry

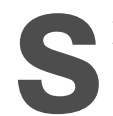
pirometry is the most frequently performed pulmonary function test and is an essential tool for the diagnosis and follow-up of respiratory diseases. Handheld office spirometers are now widely available for use in primary care and improvements in spirometry software have resulted in access to improved spirometric tests. Several studies emphasised the importance of spirometry in primary care, as a screening tool for the early detection of chronic obstructive pulmonary disease (COPD) [1-4]. This has resulted in the need for easy-to-perform spirometry tests. Increasing evidence showed that the forced expiratory volume in six seconds (FEV6) [5], can be used

For Editorial comments see page 245. as a convenient alternative for forced vital capacity (FVC) [6-9]. The use of six seconds expiratory manoeuvres makes office spirometry easier and faster, providing a more explicit end-of-test definition and reduces the risk of syncope [10].

An important issue in spirometry is the definition of abnormality. The American Thoracic Society and the European Respiratory Society (ERS) guidelines recommend the use of reference equations, derived from a representative sample of healthy subjects, to determine lower limits of normal (LLN) $[11,12]$, taking into account that the spirometric indices are influenced by age, height, sex and ethnicity. It has already been demonstrated that FEV1/FEV6 is a valid alternative for FEV1/FVC

\section{AFFILIATIONS}

*Dept of General Practice and

\#Respiratory Division, Academic Hospital, University of Brussels,

Brussels, Belgium.

CORRESPONDENCE

J. Vandevoorde

University of Brussels (Vrije

Universiteit Brussel)

Dept of General Practice

Laarbeeklaan 103

B-1090 Brussels

Belgium

Fax: 3252373311

E-mail: Jan.Vandevoorde@vub.ac.be

Received:

March 252005

Accepted after revision:

September 082005 
when using LLN based on the third National Health and Nutrition Examination Survey (NHANES III) reference equations [6, 7,9]. At present, spirometers, and in particular handheld spirometers, do not always provide reference equation-based LLN. Moreover, reference equations for FEV6 and FEV1/FEV6 are only available for the USA population (NHANES III survey) [13] and only recently for European subjects in the 65-85-yrs category [14]. Adding to the complexity of the problem, reference equations obtained from different studies lead to significant differences in predicted FVC and FEV1 [15].

Presently, it is common practice to determine airway obstruction by use of a fixed cut-off point, i.e. when FEV1/FVC is $<70 \%$, according to the Guidelines from the Global Initiative for Chronic Obstructive Lung Disease (GOLD) [16].The aim of this study is to determine an alternative for the fixed cut-off points of $\mathrm{FEV} 1 / \mathrm{FVC}<70 \%$ and $\mathrm{FVC}<80 \%$ predicted suitable for the use of FEV1/FEV6 and FEV6, respectively.

\section{METHODS}

The data of consecutive adult patients, referred to the lung function laboratory of the Academic Hospital of the University of Brussels (AZ-VUB, Brussels, Belgium), between February 1992 and December 2000, were analysed. Spirometry measurements were performed with a mass-flow sensor (SensorMedics model 2200, Viasys Health Care, Yorba Linda, CA, USA), by highly trained and experienced pulmonary function technicians, according to the guidelines of the ERS [12].

For the diagnosis of airway obstruction, FEV1/FVC $<70 \%$ was used as a fixed cut-off point, according to the GOLD guidelines [16]. From a receiver-operator characteristic (ROC) curve, the FEV1/FEV6 ratio, that corresponded to the optimal combination of sensitivity and specificity (i.e. the greatest sum of both), was determined.

A subject was said to have a restrictive spirometric pattern if there was a reduced FVC in the presence of a normal FEV1/ FVC. A fixed cut-off of $80 \%$ of the predicted value for FVC was used as the "gold standard". The FEV6 value that corresponded to the optimal combination of sensitivity and specificity was determined from a ROC curve.

To calculate sensitivity and specificity for FEV1/FEV6 and FEV6 as a predictor for obstruction or a restrictive spirometric pattern, $2 \times 2$ tables were used. For both indices the positive predictive value $(\mathrm{PPV})$ and the negative predictive value
(NPV) were also calculated. The PPV represents the proportion of patients with abnormal test results who have the disease and the NPV represents the proportion of patients with normal test results who do not have the disease. Furthermore, in each analysis the discordant cases, i.e. false positives and false negatives, were scrutinised.

Finally, agreement between the two categorisation schemes, based either on FVC or on FEV6, was assessed using kappa statistics: the number of obstructive patients were determined using $\mathrm{FEV} 1 / \mathrm{FVC}<70 \%$ as a fixed cut-off point. In the nonobstructive patients, a restrictive spirometric pattern was considered if FVC $<80 \%$ of the predicted value. Similarly, the cut-offs, obtained by a ROC curve for FEV1/FEV6 and FEV6, were used as a fixed cut-off to determine the number of patients with a normal, obstructive or restrictive spirometric pattern. The resulting classifications, based on either FVC- or FEV6-related indices, were combined in a $3 \times 3$ table, and a kappa value was calculated. Kappa represents the agreement between the two categorisation schemes in excess of the amount of agreement that would be expected by chance.

\section{RESULTS}

The same study population was used as in a previous study, by the current authors [9], comparing FEV6 and FVC using LLN determined with the NHANES III reference equations [13]. Spirometric data from 11,676 Caucasian subjects were studied, of whom 7,010 (60\%) were male and 4,666 (40\%) were female. Subject characteristics are shown in table 1 . In this table, FEV1/FVC $<70 \%$ and FVC $<80 \%$ pred were used for the diagnosis of obstruction and a restrictive pattern, respectively.

The obstructive group was further classified into subgroups according to the severity of airway obstruction in accordance with the GOLD guidelines [16]: FEV1/FVC $<70 \%$, in combination with $\mathrm{FEV} 1 \geqslant 80 \%$ pred (Stage I), or $50 \% \leqslant \mathrm{FEV} 1<80 \%$ pred (Stage II), or $30 \% \leqslant \mathrm{FEV} 1<50 \%$ pred (Stage III), or FEV1 $\leqslant 30 \%$ pred (Stage IV).

\section{Spirometric diagnosis of obstruction}

Considering FEV1/FVC $<70 \%$ as being the 'gold standard' for obstruction, a ROC curve was used to determine the best corresponding cut-off for FEV1/FEV6 (fig. 1). The area under the ROC curve was $98.8 \%$ (95\% confidence interval (CI): $98.6-$ $98.9 \%$ ), and the FEV1/FEV6 cut-off, corresponding to the greatest sum of sensitivity and specificity, was $73 \%$. When using a FEV1/FEV6 cut-off of $76 \%$, sensitivity reached $100 \%$, but specificity dropped to $71.7 \%$. Choosing a fixed cut-off of

TABLE 1 Subject demographics, presence and severity of airway obstruction

\begin{tabular}{|c|c|c|c|c|c|c|c|c|c|}
\hline & Subjects $n$ & Age yrs & Height $\mathbf{c m}$ & \multicolumn{2}{|c|}{ Not obstructed } & \multicolumn{4}{|c|}{ Obstructed $^{\#}$} \\
\hline Female & 4666 & $56(20-80)$ & $163(135-185)$ & $2550(54.7)$ & $430(9.2)$ & $393(8.4)$ & $844(18.1)$ & $366(7.8)$ & $83(1.8)$ \\
\hline Total & 11676 & $59(20-80)$ & $170(135-203)$ & $5376(46.0)$ & $943(8.1)$ & $1288(11.0)$ & 2520 (21.6) & 1192 (10.2) & $357(3.1)$ \\
\hline
\end{tabular}

Data presented as median (range) or $\mathrm{n}(\%)$ unless otherwise stated. * : using forced expiratory volume in one second/forced vital capacity (FVC) $<70 \%$ as a fixed cut-off. : using FVC $<80 \%$ predicted as a fixed cut-off. 


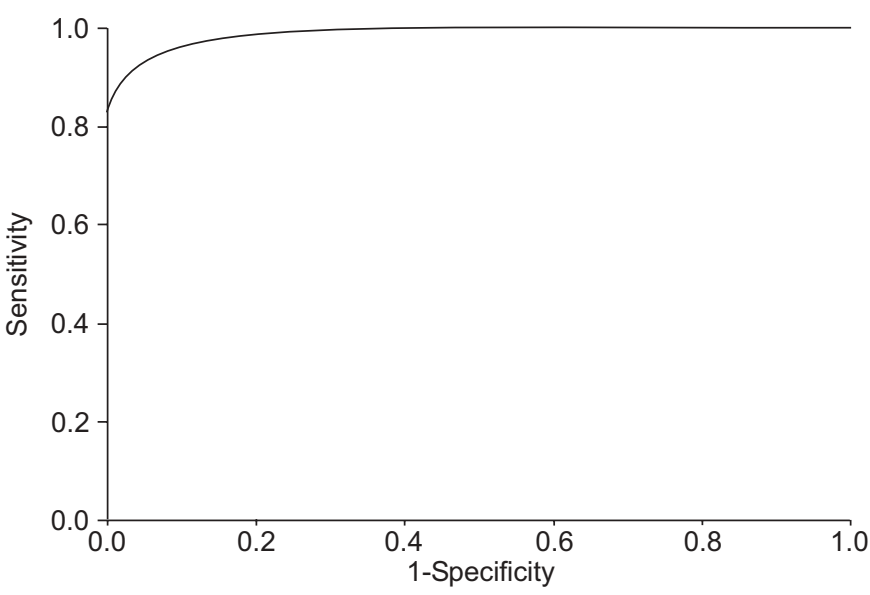

FIGURE 1. Receiver-operator characteristic curve for forced expiratory volume in one second $\left(\mathrm{FEV}_{1}\right) / \mathrm{FEV} 6$ using $\mathrm{FEV} 1 /$ forced vital capacity $<70 \%$ as a "gold standard" for obstruction.

FEV1/FEV6 $<70 \%$ resulted in a specificity of $100 \%$, with a sensitivity of $84.4 \%$. Table 2 shows the sensitivity and specificity results using $\mathrm{FEV} 1 / \mathrm{FEV}_{6}<73 \%$ as a fixed cut-off. For the total population, FEV1/FEV6 sensitivity and specificity were 94.4 and $93.3 \%$, respectively. The PPV and NPV were 92.2 and $95.2 \%$, respectively. The prevalence of obstruction was $45.9 \%$. Similar results were obtained when considering male and female subjects separately (data not shown).

Analysis of the 726 discordant cases (false positives and false negatives combined) showed that $98.8 \%$ of the discordant values of $\mathrm{FEV} 1 / \mathrm{FEV} 6$ are within a $\pm 5 \%$ interval of the chosen fixed cut-off of $73 \%$. Only one subject was found to have a FEV1/FEV6 which differed by $>10 \%$ from the cut-off.

In the 426 false positive cases, the mean difference of FEV1/ FVC and FEV1/FEV6, with their respective LLN, was 0.9 $(\mathrm{SD}=1.0)$ and $-2.1 \%(\mathrm{SD}=1.0 \%)$. In the 300 false negative cases the mean difference of FEV1/FVC and FEV1/FEV6 with their respective $\mathrm{LLN}$ was $-3.6(\mathrm{SD}=2.6)$ and $1.5 \%(\mathrm{SD}=2.0 \%)$.

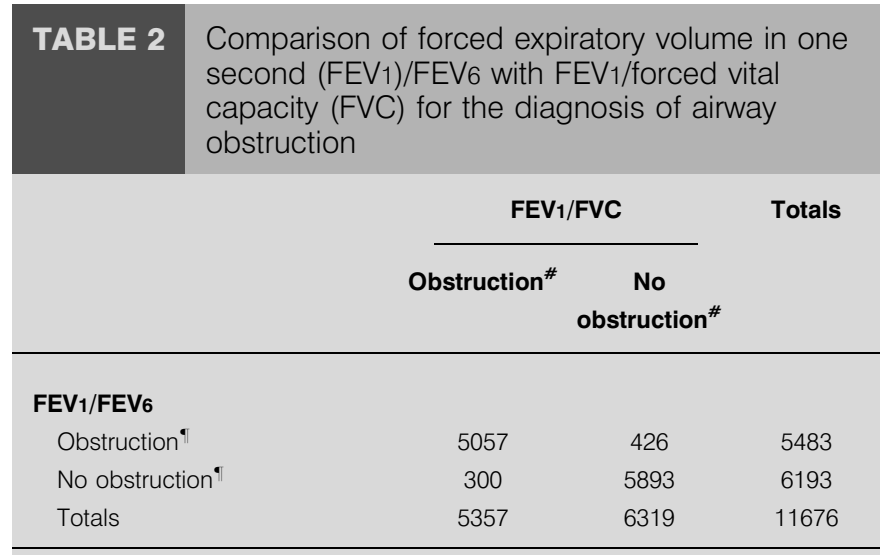

Given as \% (95\% confidence interval) sensitivity: 94.4 (93.8-95.0); specificity: 93.3 (92.6-93.9); positive predictive value: 92.2 (91.5-92.9); negative predictive value: 95.2 (94.6-95.7); prevalence of obstruction: 45.9\%. *: using FEV $1 / F V C$ $<70 \%$ as a fixed cut-off; " $"$ : using FEV $1 / F E V_{6}<73 \%$ as a fixed cut-off.

\section{Spirometric detection of restriction}

In all subjects with normal FEV1/FVC $(n=6,319)$, FVC $<80 \%$ pred was considered as a 'gold standard' for the detection of a restrictive spirometric pattern. A ROC analysis showed that a fixed cut-off of FEV6 $<82 \%$ pred resulted in the best combination (i.e. greatest sum) of sensitivity and specificity (fig. 2). The area under the ROC curve was 99.5\% (95\% $\mathrm{CI}=99.5-99.6 \%$ ). When using $\mathrm{FEV}_{6}<84 \%$ pred, sensitivity reached $100 \%$ with a specificity of $95.5 \%$. Choosing FEV $6<80 \%$ resulted in a specificity of $100 \%$, but sensitivity dropped to $88 \%$. Table 3 shows the current findings using FEV6 $<82 \%$ pred as a fixed cut-off. For the total population, sensitivity and specificity was 95.9 and $98.6 \%$, respectively. The PPV was $92.2 \%$ and the NPV $99.3 \%$. The prevalence of a restrictive pattern was $14.9 \%$. Similar results were obtained for both male and female populations (data not shown).

Analysis of the 116 discordant cases (false positives and false negatives combined) showed that $94.0 \%$ of the discordant values of FEV 6 are within a $\pm 5 \%$ interval of the chosen fixed cut-off of $82 \%$ pred. None of these results differed by $>10 \%$ with the cut-off (data not shown).

In the 77 false positive cases, the mean difference of FVC and FEV6, with their respective cut-offs, was $1.1(\mathrm{SD}=1.4)$ and $-2.5 \%$ $(\mathrm{SD}=1.6 \%)$. In the 39 false negative cases, the mean difference of FVC and FEV6 with their respective cut-off was $-1.8(\mathrm{SD}=0.8)$ and $0.5 \%(\mathrm{SD}=0.7 \%)$.

\section{Overall agreement using kappa statistics}

Overall agreement between the two categorisation schemes was assessed using kappa statistics (table 4). In this study, a kappa value of $0.87(95 \% \mathrm{CI}=0.86-0.88)$ was obtained, indicating a very good agreement between FEV6- and FVCderived indices.

\section{DISCUSSION}

It has already been demonstrated that FEV6 is a reliable alternative for FVC to identify obstructive and restrictive spirometric patterns, using the NHANES III reference equations to calculate LLN for each spirometric index [7-9]. The

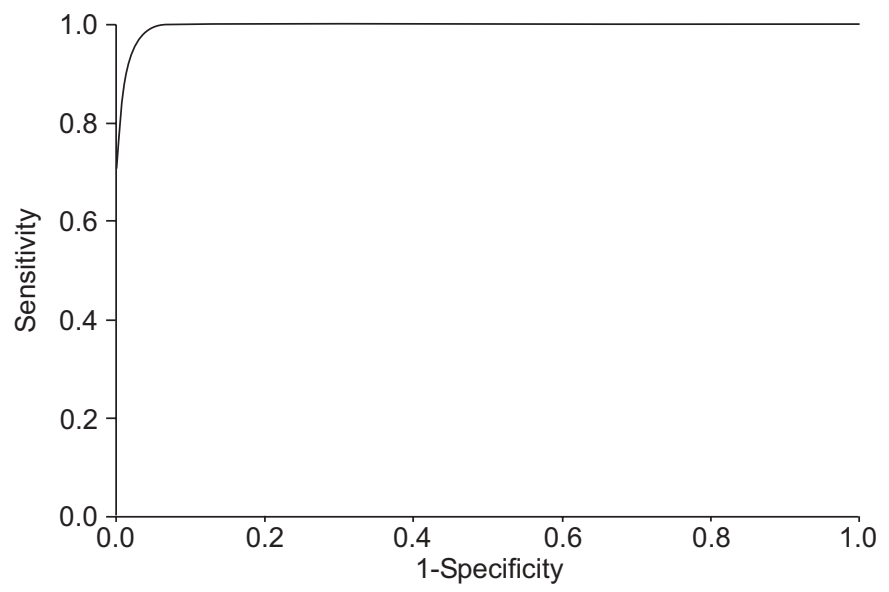

FIGURE 2. Receiver-operator characteristic curve for forced expiratory volume in six seconds using forced vital capacity $<80 \%$ predicted as a "gold standard" for restriction. 


\begin{tabular}{|c|c|c|c|}
\hline \multirow[t]{3}{*}{ TABLE 3} & \multicolumn{3}{|c|}{$\begin{array}{l}\text { Comparison of forced expiratory volume in six } \\
\text { seconds (FEV6) with forced vital capacity (FVC) } \\
\text { for the diagnosis of a spirometric restrictive } \\
\text { pattern: in the nonobstructive group }\end{array}$} \\
\hline & \multicolumn{3}{|c|}{ FVC } \\
\hline & Reduced $^{\#}$ & Normal $^{\#}$ & Total \\
\hline \multirow{3}{*}{$\begin{array}{l}\text { FEV6 reduced" } \\
\text { FEV } 6 \text { normal } \\
\text { Total } n\end{array}$} & 904 & 77 & 981 \\
\hline & 39 & 5299 & 5338 \\
\hline & 943 & 5376 & 6319 \\
\hline \multicolumn{4}{|c|}{$\begin{array}{l}\text { Given as \% (95\% confidence interval) sensitivity: } 95.9 \text { (94.4-97.0); specificity: } \\
\text { 98.6 (98.2-98.9); positive predictive value: } 92.2 \text { (90.3-93.8); negative predictive } \\
\text { value: } 99.3 \text { (99.0-99.5); prevalence of a restrictive pattern: } 14.9 \%{ }^{*} \text { : using FVC } \\
<80 \% \text { predicted as a fixed cut-off; }{ }^{\circ} \text { : using FEV6 <82\% pred as a fixed cut-off. }\end{array}$} \\
\hline
\end{tabular}

main purpose of the present study was to determine a fixed cut-off for the FEV1/FEV6 ratio and for the FEV6 which are equivalent to the commonly used fixed cut-offs for the FEV1/ FVC ratio and for the FVC.

Indeed, with a kappa value of 0.87 , a very good overall performance was obtained for FEV1/FEV6 $<73 \%$ and FEV6 $<82 \%$ pred as fixed cut-offs for the detection of obstructive and restrictive spirometric patterns, respectively (table 4). A kappa value of 1 indicates perfect agreement, while a kappa value of 0 indicates that agreement is no better than chance. LANDIS and $\mathrm{KoCH}$ [17] have proposed the following as standards for strength of agreement for the kappa coefficient: 0.01$0.20=$ slight, $0.21-0.40=$ fair, $0.41-0.60=$ moderate, $0.61-0.80=$ substantial and $0.81-1=$ almost perfect agreement.

\section{Spirometric diagnosis of obstruction}

A ROC curve analysis showed that FEV1/FEV $6<73 \%$ was the cut-off with the best combination of sensitivity and specificity, and performed well as a surrogate for FEV1/FVC $<70 \%$ (table 2). In addition, almost all of the discordant cases were close to the cut-off value.

\begin{tabular}{|c|c|c|c|c|}
\hline \multirow[t]{3}{*}{ TABLE 4} & \multicolumn{4}{|c|}{$\begin{array}{l}\text { Kappa statistics comparing forced expiratory } \\
\text { volume in six seconds (FEV6) and forced vital } \\
\text { capacity (FVC) derived indices }\end{array}$} \\
\hline & \multicolumn{4}{|c|}{$\mathrm{FVC}^{\#}$} \\
\hline & Normal & Obstruction & Restriction & Total \\
\hline \multicolumn{5}{|l|}{ FEV $6^{\circ}$} \\
\hline Normal & 4992 & 226 & 67 & 5285 \\
\hline Obstruction & 325 & 5057 & 101 & 5483 \\
\hline Restriction & 59 & 74 & 775 & 908 \\
\hline Total & 5376 & 5357 & 943 & 11676 \\
\hline $\begin{array}{l}\# \text { : using FEV } 1 \\
\text { obstructive or } \\
<73 \% \text { and } F \\
\text { restrictive spirc }\end{array}$ & $\begin{array}{l}V_{6}<82 \% \text { predic } \\
\text { metric pattern, re }\end{array}$ & $\begin{array}{l}\text { VC }<80 \% \text { prec } \\
\text { tric pattern, res } \\
\text { ted as fixed c } \\
\text { pectively. Kapp }\end{array}$ & $\begin{array}{l}\text { cted as fixed } \\
\text { ectively; } \because \text { us } \\
\text { t-offs for an } \\
=0.87 \text {. }\end{array}$ & $\begin{array}{l}\text { offs for } \\
\text { FEV } 1 / F E \\
\text { tructive }\end{array}$ \\
\hline
\end{tabular}

The findings of the present study apply to a population with an overall prevalence of airway obstruction of $45.9 \%$, which corresponds to reported prevalences of COPD of $30-50 \%$ in high-risk populations, i.e. smokers aged $>45$ yrs and subjects with respiratory symptoms. This makes FEV1/FEV6 suitable for screening purposes in primary care.

It should be emphasised that fixed cut-off values should be used with caution, as spirometric indices are highly influenced by age, height, sex and race. From the NHANES III survey, reference equations have become available to calculate predictive values and LLN for FEV1, FVC, FEV6, FEV1/FVC and FEV1/FEV6, with age and height as predictor variables [13]. In the study by HANKINSON et al. [13], the analysis was performed separately for each sex and each ethnic group, and the LLN was estimated as predicted minus 1.645 times the standard error of the estimate, which corresponds to the fifth percentile.

While fixed cut-off values are more widely used, in an attempt to simplify the diagnosis, there is potential for misclassification. For example, in elderly subjects, where the age-related decline in FEV1/FVC and FEV1/FEV6 may cause a significant

TABLE 5 Age and sex dependency of the lower limits of normal (LLN) ${ }^{\#}$ for forced expiratory volume in one second (FEV1)/forced vital capacity (FVC) and FEV1/FEV6

\begin{tabular}{|c|c|c|c|c|c|c|c|c|}
\hline \multirow[t]{2}{*}{ Age yrs } & \multicolumn{4}{|c|}{ Male } & \multicolumn{4}{|c|}{ Female } \\
\hline & FEV $_{1} /$ FVC & $\Delta \mathrm{FEV}_{1} / \mathrm{FVC}$ & $\mathrm{FEV}_{1 / \mathrm{FEV}}$ & $\Delta$ FEV $_{1} /$ FEV $_{6}$ & FEV $_{1} /$ FVC & $\Delta$ FEV $_{1} /$ FVC & $F E V_{1} / F E V_{6}$ & $\Delta$ FEV $_{1} / \mathrm{FEV}_{6}$ \\
\hline 20 & 74.3 & 4.3 & 75.6 & 2.6 & 76.8 & 6.8 & 78.2 & 5.2 \\
\hline 30 & 72.2 & 2.2 & 74.2 & 1.2 & 74.6 & 4.6 & 76.6 & 3.6 \\
\hline 40 & 70.1 & 0.1 & 72.8 & -0.2 & 72.5 & 2.5 & 75.1 & 2.1 \\
\hline 50 & 68.1 & -1.9 & 71.5 & -1.5 & 70.4 & 0.4 & 73.5 & 0.5 \\
\hline 60 & 66.0 & -4.0 & 70.1 & -2.9 & 68.3 & -1.7 & 71.9 & -1.1 \\
\hline 70 & 63.9 & -6.1 & 68.7 & -4.3 & 66.1 & -3.9 & 70.4 & -2.6 \\
\hline 80 & 61.9 & -8.1 & 67.3 & -5.7 & 64.0 & -6.0 & 68.8 & -4.2 \\
\hline
\end{tabular}

Data presented as \% predicted. $\Delta$ FEV1/FVC: difference between the LLN and the fixed cut-off FEV $1 / F V C<70 \% ; \Delta F E V_{1} / F E V_{6}$ : difference between the LLN and the fixed cut-off FEV $1 / F_{6}<73 \%$. * : LLN based on the third National Health and Nutrition Examination Survey reference equations for Caucasian subjects [13]. 


\begin{tabular}{|c|c|c|c|c|c|c|c|c|c|c|c|c|}
\hline TABLE 6 & $\begin{array}{l}\mathrm{Ag} \\
\text { vol }\end{array}$ & $\begin{array}{l}\text { heigh } \\
\text { in six } s\end{array}$ & $\begin{array}{l}\text { pend } \\
\text { nds ( }\end{array}$ & $\begin{array}{l}\text { of the } \\
\text { ) in mal }\end{array}$ & limi & norma & N) ${ }^{\#} \mathrm{O}$ & ced vitc & oacit & VC) ar & ced & iratory \\
\hline \multirow{3}{*}{$\begin{array}{l}\text { Age } \\
\text { yrs }\end{array}$} & \multicolumn{12}{|c|}{ Height $\mathrm{cm}$} \\
\hline & \multicolumn{4}{|c|}{165} & \multicolumn{4}{|c|}{175} & \multicolumn{4}{|c|}{185} \\
\hline & $\begin{array}{l}\text { FVC } \\
\text { LLN }\end{array}$ & $\begin{array}{c}\text { FVC \% } \\
\text { pred }\end{array}$ & $\begin{array}{l}\text { FEV6 } \\
\text { LLN }\end{array}$ & $\begin{array}{c}\text { FEV6 } \% \\
\text { pred }\end{array}$ & $\begin{array}{l}\text { FVC } \\
\text { LLN }\end{array}$ & $\begin{array}{l}\text { FVC } \% \\
\text { pred }\end{array}$ & $\begin{array}{l}\text { FEV } 6 \\
\text { LLN }\end{array}$ & $\begin{array}{c}\text { FEV6 } \% \\
\text { pred }\end{array}$ & $\begin{array}{l}\text { FVC } \\
\text { LLN }\end{array}$ & $\begin{array}{c}\text { FVC } \% \\
\text { pred }\end{array}$ & $\begin{array}{l}\text { FEV } 6 \\
\text { LLN }\end{array}$ & $\begin{array}{c}\text { FEV6 \% } \\
\text { pred }\end{array}$ \\
\hline 20 & 4.0 & 83 & 4,0 & 84 & 4.5 & 83 & 4.5 & 84 & 5.1 & 83 & 5.1 & 84 \\
\hline 30 & 3.9 & 83 & 3.8 & 83 & 4.4 & 83 & 4.3 & 83 & 5.0 & 83 & 4.9 & 83 \\
\hline 40 & 3.7 & 82 & 3.6 & 82 & 4.2 & 82 & 4.1 & 82 & 4.8 & 83 & 4.7 & 83 \\
\hline 50 & 3.4 & 81 & 3.3 & 81 & 4.0 & 81 & 3.8 & 81 & 4.5 & 82 & 4.4 & 82 \\
\hline 60 & 3.1 & 80 & 3.0 & 79 & 3.7 & 80 & 3.5 & 80 & 4.2 & 81 & 4.0 & 80 \\
\hline
\end{tabular}

\% pred: percentage of predicted. ${ }^{\#}:$ LLN based on the third National Health and Nutrition Examination Survey reference equations for Caucasian subjects [13]

TABLE 7 Age and height dependency of the lower limits of normal $(L L N)^{\#}$ of forced vital capacity (FVC) and forced expiratory volume in six seconds (FEV6) in females

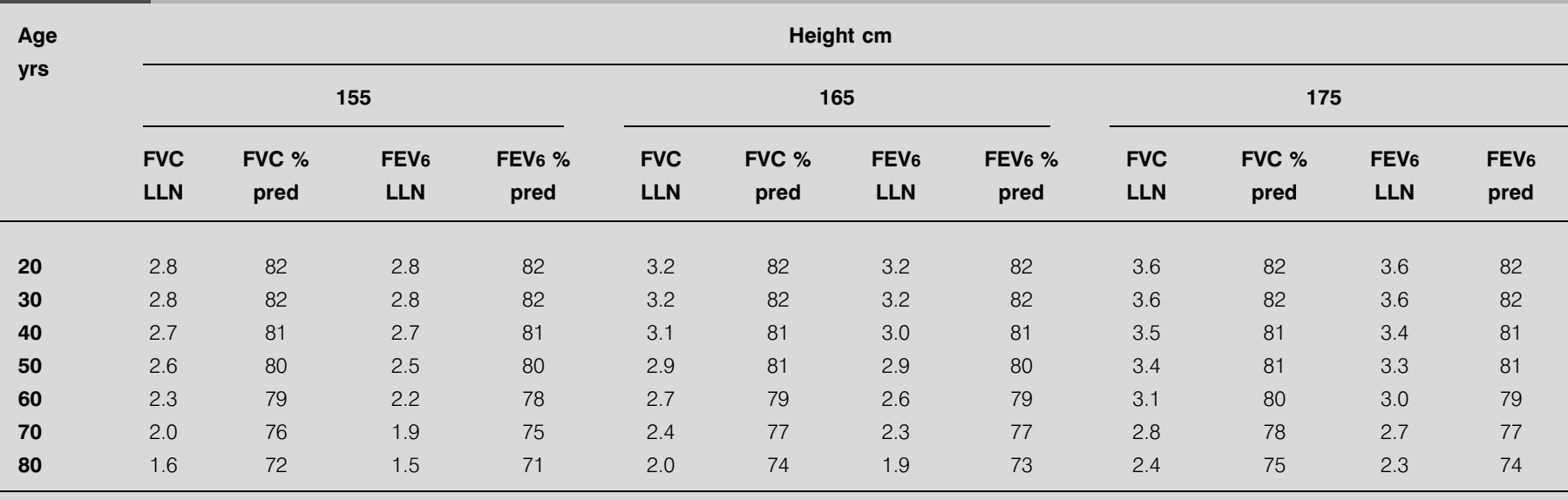

\% pred: percentage of predicted. ${ }^{\#}$ : LLN based on the third National Health and Nutrition Examination Survey reference equations for Caucasian subjects [13]

over-diagnosis of airway obstruction, pointed out by HARDIE et al. [18]. This is illustrated here by table 5 where LLN values, derived from the NHANES III reference equations, are depicted for discrete ages between 20-80 yrs. Clearly, fixed cut-offs of FEV1/FVC $<70 \%$ and FEV1/FEV $6<73 \%$ are most suitable for use with middle-aged subjects. Table 5 also shows that cut-offs could be $7 \%$ (for FEV1/FVC) or $5 \%$ (for FEV1/ FEV6) higher in 20-yr-old females and $8 \%$ (for FEV1/FVC) or $6 \%$ (for FEV1/FEV6) lower in 80-yr-old males. Finally, it must be considered that, regardless of the method used to define abnormality, measured values that lie close to the threshold should be interpreted with caution, due to several sources of variability: 1) diurnal and day-to-day variations of spirometric indices [11]; 2) between-manoeuvre repeatability criteria that allow for a difference up to a maximum of $0.150 \mathrm{~L}$ between the two largest values of both FEV1 and FVC [5]; 3) patients with obstruction having coefficients of variation for FEV1 and FVC that are approximately twice those of normal subjects [19].

\section{Spirometric detection of restriction}

The present study shows that the commonly used cut-off value, $\mathrm{FVC}<80 \%$ predicted, could be replaced by $\mathrm{FEV}_{6}<82 \%$ pred, especially for excluding a restrictive ventilatory defect. However, a restrictive abnormality is characterised by a reduced total lung capacity, whereas a reduced FVC in the presence of a normal FEV1/FVC can only be used to suggest, but not to diagnose, the presence of a restrictive abnormality [11]. A study by SwANNEY et al. [8] showed that spirometrybased algorithms could not reliably predict a reduced total lung capacity, but are very useful at excluding a restrictive defect. They also demonstrated that FEV6 was equivalent to FVC when using LLN calculated with the NHANES III reference equations. In the current study high, negative predictive values were found when comparing FEV6 and FVC as a predictor of a restrictive pattern (table 3 ). This makes the use of FEV6 suitable for the exclusion of restriction. 
However, fixed percentages of the predicted value should be used with caution. Tables 6 and 7 show the age and height dependency of the LLN for FVC and FEV6, using the NHANES III reference equations, for males and females. Using fixed cutoffs had a tendency towards over-diagnosis of a restrictive pattern in elderly people.

\section{CONCLUSION}

This study demonstrates that forced expiratory volume in one second/forced expiratory volume in six seconds $<73 \%$ and forced expiratory volume in six seconds $<82 \%$ pred can be used as a valid alternative for forced expiratory volume in one second/forced vital capacity $<70 \%$ and forced vital capacity $<80 \%$ pred as fixed cut-off points for the detection of an obstructive or restrictive spirometric pattern in adults. The authors emphasise that the fixed cut-off terms should be used with caution, particularly outside the middle-aged population. Ideally, abnormalities in spirometric values should be defined using lower limits of normal, derived from a representative sample of healthy subjects.

\section{REFERENCES}

1 Buffels J, Degryse J, Heyrman J, Decramer M. Office spirometry significantly improves early detection of COPD in general practice. The DIDASCO Study. Chest 2004; 125: 1394-1399.

2 Lundbäck B, Lindberg A, Lindström M, et al. Not 15 but $50 \%$ of smokers develop COPD? Report from the Obstructive Lung Disease in Northern Sweden Studies. Respir Med 2003; 97: 115-122.

3 Stratelis G, Jakobsson P, Molstad S, Zetterstrom O. Early detection of COPD in primary care: screening by invitation of smokers aged 40 to 55 years. Br J Gen Pract 2004; 54: 201-206.

4 Zieliñski J, Bednarek M. Early Detection of COPD in a high-risk population using spirometric screening. Chest 2001; 119: 731-736.

5 Miller MR, Hankinson JL, Brusasco V, et al. Standardisation of spirometry. Eur Respir J 2005; 26: 319-338.

6 Enright PL, Connett JE, Bailey WC. The FEV1/FEV6 predicts lung function decline in adult smokers. Respir Med 2002; 96: 444-449.

7 Swanney MP, Jensen RL, Crichton DA, Beckert LE, Cardno LA, Crapo RO. FEV6 is an acceptable surrogate for FVC in the spirometric diagnosis of airway obstruction and restriction. Am J Respir Crit Care Med 2000; 162: 917-919.
8 Swanney MP, Beckert LE, Frampton CM, Wallace LA, Jensen RL, Crapo RO. Validity of the American Thoracic Society and other spirometric algorithms using FVC and forced expiratory volume at $6 \mathrm{~s}$ for predicting a reduced total lung capacity. Chest 2004; 26: 1861-1866.

9 Vandevoorde J, Verbanck S, Schuermans D, Kartounian J, Vincken W. FEV1/FEV6 and FEV6 as an alternative for FEV1/FVC and FVC in the spirometric detection of airway obstruction and restriction. Chest 2005; 127: 1560-1564.

10 Ferguson GT, Enright PL, Buist AS, Higgins MW. Office spirometry for lung health assessment in adults: a consensus statement from the National Lung Health Education Program. Chest 2000; 117: 1146-1161.

11 Medical Section of the American Lung Association. Lung function testing: selection of reference values and interpretative strategies. Am Rev Respir Dis 1991; 144: 1202-1218.

12 Quanjer PhH, Tammeling GJ, Cotes JE, Pedersen OF, Peslin R, Yernault JC. Standardized lung function testing. Lung volumes and forced ventilatory flows. Eur Respir J 1993; 16: Suppl. 6, 5s-40s.

13 Hankinson JL, Odencrantz JR, Fedan KB. Spirometric reference values from a sample of the general U.S population. Am J Respir Crit Care Med 1999; 159: 179-187.

14 Garcia-Rio F, Pino JM, Dorgham A, Alonso A, Villamor J. Spirometric reference equations for European females and males aged 65-85 yrs. Eur Respir J 2004; 24: 397-405.

15 Roca J, Burgos F, Sunyer J, et al. Reference values for forced spirometry. Eur Respir J 1998; 11: 1354-1362.

16 U.S. Public Health Service National Heart, Lung and Blood Institute. Global Initiative for Chronic Obstructive Lung Disease: Global Strategy for the Diagnosis, Management, and Prevention of Chronic Obstructive Pulmonary Disease, 2004. www.goldcopd.com. Last updated: July 2005; last accessed: May 2005.

17 Landis JR, Koch GG. The measurement of observer agreement for categorical data. Biometrics 1977; 33: 159-174.

18 Hardie JA, Buist AS, Vollmer WM, Ellingsen I, Bakke PS, Morkve O. Risk of over-diagnosis of COPD in asymptomatic elderly never-smokers. Eur Respir J 2002; 20: 1117-1122.

19 Pennock BE, Rogers RM, McCaffree DR. Changes in measured spirometric indices: what is significant? Chest 1981; 80: 97-99. 